\title{
Contribution of the Photo-Fenton Reaction to Hydroxyl Radical Formation Rates in River and Rain Water Samples
}

\author{
Nobutake NaKatanI, ${ }^{* * * \dagger}$ Marina Ueda, ${ }^{* *}$ Hirotaka ShIndo, ${ }^{* *}$ Kazuhiko TAKEDA, ${ }^{* *}$ and \\ Hiroshi SaKugawa** \\ * Graduate School for International Development and Cooperation, Hiroshima University, \\ 1-5-1 Kagamiyama, Higashi-Hiroshima 739-8529, Japan \\ **Graduate School of Biosphere Science, Hiroshima University, \\ 1-7-1 Kagamiyama, Higashi-Hiroshima 739-8521, Japan
}

\begin{abstract}
The hydroxyl radical (OH radical) formation rates from the photo-Fenton reaction in river and rain water samples were determined by using deferoxamine mesylate (DFOM), which makes a stable and strong complex with Fe(III), resulting in a suppression of the photo-Fenton reaction. The difference between the $\mathrm{OH}$ radical formation rates with and without added DFOM denotes the rate from the photo-Fenton reaction. The photoformation rates from the photo-Fenton reaction were in the range of $0.7-45.8 \times 10^{-12}$ and $2.7-32.3 \times 10^{-12} \mathrm{M} \mathrm{s}^{-1}$ in river and rain water samples, respectively. A strong positive correlation between the $\mathrm{OH}$ radical formation rate from the photo-Fenton reaction and the amount of fluorescent matter in river water suggests that fluorescent matter, such as humic substances, plays an important role in the photoFenton reaction. In rain water, direct photolysis of hydrogen peroxide was an important source of $\mathrm{OH}$ radicals as well as the photo-Fenton reaction. The contributions of the photo-Fenton reaction to the $\mathrm{OH}$ radical photoformation rates in river and rain water samples were in the ranges of $2-29$ and 5-38\%, respectively. Taking into account the photo-Fenton reaction, 33-110 (mean: 80) and 42-110 (mean: 84)\% of $\mathrm{OH}$ radical sources in river and rain water samples, respectively, collected in Hiroshima prefecture were elucidated.
\end{abstract}

(Received June 18, 2007; Accepted July 23, 2007; Published September 10, 2007)

\section{Introduction}

The hydroxyl radical (OH radical), which is the most oxidative reactant among the active oxygen species, ${ }^{1,2}$ is generated as a short-lived intermediate in rain and river water by photochemical reactions under natural sunlight irradiation. ${ }^{3-8}$ Because of its high reactivity (second-order rate constant of the $\mathrm{OH}$ radical with organic compounds: $\left.10^{8}-10^{10} \mathrm{M}^{-1} \mathrm{~s}^{-1}\right),{ }^{9}$ the $\mathrm{OH}$ radical plays an important role in the transformation of organic compounds, especially recalcitrant organic compounds, such as those resistant to chemical, biological and direct photochemical degradation in natural water. ${ }^{10,11}$ For example, the reaction of the photo-formed $\mathrm{OH}$ radical with bisphenol $\mathrm{A}$, a compound that is resistant to direct photochemical degradation under natural sunlight irradiation, has a significant effect on the fate of bisphenol A in river water. ${ }^{7}$ Similarly, it has been suggested that the oxidation of polychlorinated biphenyls (PCBs), a persistent group of organic pollutants, with $\mathrm{OH}$ radicals can affect the fate of PCBs in natural water. ${ }^{12}$ Furthermore, the reaction of $\mathrm{OH}$ radicals with inorganic compounds, such as S(IV) species in atmospheric water, has been proposed as a pathway for the generation of sulfate. ${ }^{13}$ In order to understand the effect of the $\mathrm{OH}$ radical on the behavior of organic and inorganic compounds in natural water under sunlight irradiation, it is important to determine the photochemical formation rate of the $\mathrm{OH}$ radical and to clarify its formation mechanism.

$\uparrow$ To whom correspondence should be addressed.

E-mail: nnakatan@hiroshima-u.ac.jp
There are several mechanisms of $\mathrm{OH}$ radical photoformation in natural water: direct photolysis of nitrite $\left(\mathrm{NO}_{2}-/ \mathrm{HNO}_{2}\right)$, nitrate ions $\left(\mathrm{NO}_{3}^{-}\right)$and hydrogen peroxide $\left(\mathrm{H}_{2} \mathrm{O}_{2}\right){ }^{14,15}$ In our previous studies, the total contribution of $\mathrm{OH}$ radicals from direct photolysis of $\mathrm{NO}_{2}{ }^{-}, \mathrm{NO}_{3}{ }^{-}$and $\mathrm{H}_{2} \mathrm{O}_{2}$ accounted for 10 to $80 \%$ of the $\mathrm{OH}$ radical photoformation rate in river water. ${ }^{6-8}$ The mean contributions to $\mathrm{OH}$ radical production from the photolysis of $\mathrm{NO}_{2}{ }^{-}$and $\mathrm{NO}_{3}{ }^{-}$in rain water were only 7.8 and $28.4 \%$, respectively, while almost all of the $\mathrm{OH}$ radicals in dew water were derived from the photolysis of $\mathrm{NO}_{2}{ }^{-5}$. Consequently, unknown sources of $\mathrm{OH}$ radical photoformation still remain in both river and rain water. Furthermore, although the $\mathrm{OH}$ radical photoformation rate from unknown sources was strongly correlated to the amount of fluorescent matter (FM) in river water, ${ }^{6}$ the role of $\mathrm{FM}$ in $\mathrm{OH}$ radical photoformation is not clear. $\mathrm{Fe}(\mathrm{III})$, which exists in the form of complexes with natural dissolved organic matter (DOM), such as humic substances in natural water, is photochemically reduced to $\mathrm{Fe}$ (II) under sunlight irradiation through a ligand-to-metal charge transfer (reaction 1). ${ }^{16}$ In addition, the photodegradation of the $\mathrm{Fe}(\mathrm{III})$ monohydroxy complex also produces $\mathrm{Fe}(\mathrm{II})$ and the $\mathrm{OH}$ radical (reaction 2), ${ }^{17}$ while this reaction is unlikely to be a significant production mechanism of $\mathrm{Fe}(\mathrm{II})$ and the $\mathrm{OH}$ radical in natural water. $^{18}$ Reduced iron can react with $\mathrm{H}_{2} \mathrm{O}_{2}$ to produce $\mathrm{OH}$ radicals via the so-called "Fenton's reaction" (reaction 3). The photo-Fenton reaction consisting of these reactions serves as a source of $\mathrm{OH}$ radical formation in natural water.

$$
\mathrm{Fe}(\mathrm{III})-(\mathrm{DOM})_{\mathrm{m}}+\text { light } \longrightarrow \mathrm{Fe}(\mathrm{II})-\mathrm{DOM}_{\mathrm{m}-1}+\mathrm{DOM}_{\mathrm{ox}}{ }^{+}
$$




$$
\begin{aligned}
& \mathrm{Fe}(\mathrm{OH})^{2+}+\text { light } \longrightarrow \mathrm{Fe}(\mathrm{II})+\cdot \mathrm{OH} \\
& \mathrm{Fe}(\mathrm{II})+\mathrm{H}_{2} \mathrm{O}_{2} \longrightarrow \mathrm{Fe}(\mathrm{III})+\cdot \mathrm{OH}+\mathrm{OH}^{-}
\end{aligned}
$$

In this study, the contributions of the photo-Fenton reaction to $\mathrm{OH}$ radical formation in river and rain water were examined by using deferoxamine mesylate (DFOM). This compound can form a strong and stable $\mathrm{Fe}$ (III)-complex, resulting in suppression of the photo-Fenton reaction. However, the contributions of the photo-Fenton reaction to $\mathrm{OH}$ radical formation were limited in the case of highly colored, acidic and iron-rich river water. ${ }^{19}$ In addition, it is necessary to take into account other contributions to $\mathrm{OH}$ radical formation, such as the direct photolysis of $\mathrm{NO}_{2}^{-}, \mathrm{NO}_{3}^{-}$and $\mathrm{H}_{2} \mathrm{O}_{2}$. Therefore, the contribution from the photo-Fenton reaction to $\mathrm{OH}$ radical formation was also estimated together with that from the direct photolysis of these $\mathrm{OH}$ radical sources. In addition, based on the relationship between the $\mathrm{OH}$ radical formation rate from the photo-Fenton reaction and the chemical components $\left(\mathrm{H}_{2} \mathrm{O}_{2}\right.$, total iron, DOM and FM), the mechanisms of the photo-Fenton reaction in river and rain water are discussed.

\section{Experimental}

\section{Reagents and chemicals}

All chemicals and solvents used were of analytical reagent grade and were used as received. Ultra-pure water (Milli-Q water, $>18 \mathrm{M} \Omega \mathrm{cm}^{-1}$, Millipore Japan) was used for the preparation of all solutions. A stock solution of DFOM $\left(\mathrm{C}_{25} \mathrm{H}_{48} \mathrm{~N}_{6} \mathrm{O}_{8} \mathrm{H}_{4} \mathrm{O}_{3} \mathrm{~S}\right.$, Sigma-Aldrich Japan) was dissolved to give a $10 \mathrm{mM}$ solution. Potassium trisoxalate ferrate(III) was synthesized according to a method of Johnson. ${ }^{20}$

Analytical procedure for determination of $\mathrm{OH}$ radical photoformation rate

The photoformation rate of $\mathrm{OH}$ radicals was determined by a previously reported method using an automatic irradiation and injection system equipped with HPLC. ${ }^{21}$ The added benzene in water samples transformed into phenol by photo-formed $\mathrm{OH}$ radicals under artificial sunlight irradiation from a Xe lamp with an optical filter. The slope of the plot of the phenol concentration against the irradiation time shows the photoformation rate of phenol in water samples $\left(R_{\text {phenol }}\right)$. The $\mathrm{OH}$ radical photoformation rate $\left(R_{\mathrm{OH}}\right)$ was calculated by the following equation:

$$
R_{\mathrm{OH}}=\frac{R_{\text {phenol }}}{Y_{\text {phenol }} \times F_{\text {benzene, } \mathrm{OH}}},
$$

where $Y_{\text {phenol }}$ is the yield of phenol formed per benzene oxidized by $\mathrm{OH}$ radicals (mean \pm standard deviation $=0.75 \pm 0.07$ ) and $F_{\text {benzene,OH }}$ is the fraction of $\mathrm{OH}$ radicals that react with benzene. ${ }^{3}$ Using benzene as a probe of the $\mathrm{OH}$ radical at $1.2 \mathrm{mM}$, most of the $\mathrm{OH}$ radicals formed in rain and river water samples react with benzene $\left(F_{\text {benzene,OH }} \cong 1.0\right)$, ${ }^{5,6,21}$ even if the $\mathrm{OH}$ radical scavengers, such as chloride ion and DOM exist in natural water samples.

The effect of DFOM at $10 \mu \mathrm{M}$ on the suppression of $\mathrm{OH}$ radical formation from the photo-Fenton reaction was evaluated by using a mixing solution of $1 \mu \mathrm{M}$ potassium trisoxalate ferrate(III) and $0.5 \mu \mathrm{M} \mathrm{H}_{2} \mathrm{O}_{2}$ at $\mathrm{pH}$ 5.6. The effect of the addition of a variety of different DFOM concentrations $(0-10$ $\mu \mathrm{M})$ on the reaction of $\mathrm{OH}$ radicals with benzene was examined by using a solution containing $1 \mathrm{mM}$ sodium nitrate as a source of $\mathrm{OH}$ radicals at $\mathrm{pH}$ 5.6.
The phenol formation rates in a water sample with and without added DFOM at $10 \mu \mathrm{M}$ were determined and the $\mathrm{OH}$ radical formation rate was calculated for each solution. Then, the $\mathrm{OH}$ radical formation rate from the photo-Fenton reaction was obtained from the difference between the $\mathrm{OH}$ radical formation rates with and without added DFOM.

The $\mathrm{OH}$ radical formation rates from the direct photolysis of $\mathrm{NO}_{3}{ }^{-}, \mathrm{NO}_{2}{ }^{-}$and $\mathrm{H}_{2} \mathrm{O}_{2}$ were calculated by multiplying the concentration of each source in the water samples by their rate constants for $\mathrm{OH}$ radical formation. The rate constants used for $\mathrm{OH}$ radical formation from $\mathrm{NO}_{3}{ }^{-}, \mathrm{NO}_{2}{ }^{-}$and $\mathrm{H}_{2} \mathrm{O}_{2}$ were $2.76 \times 10^{-5}, 2.56 \times 10^{-7}$ and $2.76 \times 10^{-6} \mathrm{~s}^{-1}$, respectively. ${ }^{21}$ The percentage contribution from each source to the $\mathrm{OH}$ radical formation rate determined was then estimated. ${ }^{6}$

The light intensity of the irradiation system was determined by using the chemical actinometry of 2-nitrobenzaldehyde (2-NB) and the same reaction cell as that for the determination of $\mathrm{OH}$ radicals. ${ }^{21}$ The degradation rates of 2-NB $\left(J_{2-\mathrm{NB}}\right)$ obtained in the present study ranged from 0.0090 to $0.0093 \mathrm{~s}^{-1}$. In this study, the $\mathrm{OH}$ radical photoformation rates were normalized to $J_{2-\mathrm{NB}}=$ $0.0093 \mathrm{~s}^{-1}$, which was determined at noon, under clear-sky conditions in Higashi-Hiroshima city $\left(34^{\circ} \mathrm{N}\right)$ on Oct. $7,2002 .{ }^{8}$ It must be recognized that the photochemical reaction depends on both the light intensity and the wavelength of the light source. However, this normalization enables a comparison to be made between data, and a quantitative discussion on the contribution from each $\mathrm{OH}$ radical source.

\section{Other determinations}

The concentrations of anions $\left(\mathrm{Cl}^{-}, \mathrm{NO}_{3}{ }^{-}\right.$and $\left.\mathrm{SO}_{4}{ }^{2-}\right)$ and the $\mathrm{pH}$ were determined by ion chromatography (Dionex, DX-500) and a glass-electrode $\mathrm{pH}$ meter (TOA, HM30S), respectively. The nitrite ion concentration was determined by a colorimetric method, the diazotization reaction using $N$-1-naphthylethylenediamine dihydrochloride and sulfanilamide. Dissolved organic carbon (DOC) was determined by using a TOC-5000 (Shimadzu Co.). FM was determined by using a fluorescence spectrophotometer (Hitachi Ltd., F-4500) at an excitation wavelength of $320 \mathrm{~nm}$ and an emission wavelength of $420 \mathrm{~nm}$. A $2.8 \mu \mathrm{g} \mathrm{L}^{-1}$ quinine sulfate dehydrate solution (analytical grade from Nacalai Tesque, Inc.) acidified by sulfuric acid at $\mathrm{pH} 2.0$ was used as the standard for FM, in which the fluorescence intensity was taken as 25 fluorescence units (flu.). ${ }^{22}$ The total dissolved iron was determined by using inductively coupled plasma atomic emission spectrometry (Optima 3000, Perkin Elmer). The $\mathrm{H}_{2} \mathrm{O}_{2}$ concentration was determined by a method of Sakugawa et al..$^{23}$

\section{Sampling}

River-water samples were collected from the Kurose, Ohta, Seno, Ashida and Oze Rivers of Hiroshima prefecture, western Japan. Sampling was carried out from Oct. 2004 to Oct. 2005. For river-water samples collected in 2004, measurements of FM were not performed. Rain-water samples were collected on the roof of Hiroshima University from June 2005 to Nov. 2005. A polyethylene funnel with an opening of diameter $24 \mathrm{~cm}$ and a 1-L PE bottle were set out before a precipitation event, and then immediately transported to the laboratory after the event. River and rain water samples were filtered through a pre-combusted glass fiber filter (Advantec, $0.45 \mu \mathrm{m}$ nominal rating) and a nuclepore polycarbonate filter (Whatman, $0.2 \mu \mathrm{m}$ pore size). Filtered water samples were stored in the dark at $4^{\circ} \mathrm{C}$ until analysis. The chemical compositions of river and rain water samples collected are summarized in Table 1. 
Table 1 Summary of the chemical compositions of river and rain water samples collected in Hiroshima prefecture

\begin{tabular}{|c|c|c|c|c|c|c|c|}
\hline & \multirow{2}{*}{ Unit } & \multicolumn{3}{|c|}{ River } & \multicolumn{3}{|c|}{ Rain } \\
\hline & & $n$ & Mean & Min. - Max. & $n$ & Mean & Min. - Max. \\
\hline $\mathrm{pH}$ & & 20 & 7.5 & $6.7-9.0$ & 5 & 5.0 & $4.2-5.9$ \\
\hline $\mathrm{Cl}^{-}$ & $\mu \mathrm{M}$ & 29 & 341 & $123-1551$ & 9 & 8.7 & $0.2-31.0$ \\
\hline $\mathrm{NO}_{3}^{-}$ & $\mu \mathrm{M}$ & 33 & 51.2 & $2.0-197$ & 9 & 24.2 & $7.2-96.5$ \\
\hline $\mathrm{SO}_{4}{ }^{2-}$ & $\mu \mathrm{M}$ & 29 & 81.0 & $22.0-400$ & 9 & 17.2 & $0.3-63.1$ \\
\hline $\mathrm{NO}_{2}^{-}$ & $\mu \mathrm{M}$ & 33 & 1.20 & N.D. - 16.7 & 9 & 0.31 & N.D. -1.47 \\
\hline DOC & $\mathrm{mgC} \mathrm{L}^{-1}$ & 33 & 1.20 & $0.35-3.26$ & 9 & 1.01 & $0.48-2.60$ \\
\hline $\mathrm{FM}^{\mathrm{a}}$ & Flu. & 21 & 86.8 & $0.02-217$ & 8 & 9.54 & $5.17-25.6$ \\
\hline Total iron & $\mu \mathrm{M}$ & 31 & 1.04 & $0.05-7.36$ & 9 & 0.52 & N.D. -3.12 \\
\hline $\mathrm{H}_{2} \mathrm{O}_{2}$ & $\mu \mathrm{M}$ & 33 & 0.03 & N.D. -0.08 & 9 & 7.49 & $0.77-13.9$ \\
\hline
\end{tabular}

a. Excitation/emission wavelength $=320 / 420 \mathrm{~nm}$.

N.D., Not detected.

\section{Results and Discussion}

Validity of the methods used to determine the $\mathrm{OH}$ radical formation rate from the photo-Fenton reaction using DFOM

The photoformation of phenol in a mixing solution of $1 \mu \mathrm{M}$ potassium trisoxalate ferrate(III) and $0.5 \mu \mathrm{M} \mathrm{H}_{2} \mathrm{O}_{2}$, which we call the photo-Fenton solution, with and without DFOM at 10 $\mu \mathrm{M}$, is shown in Fig. 1. In the solution without DFOM, Fe(II) is produced photochemically from $\mathrm{Fe}(\mathrm{III})$ oxalate complexes, resulting in the formation of $\mathrm{OH}$ radicals by the reaction of $\mathrm{Fe}(\mathrm{II})$ and $\mathrm{H}_{2} \mathrm{O}_{2} \cdot{ }^{24}$ The slope of the plot of the phenol concentration against the irradiation time for the solution with DFOM was much smaller than that for the solution without DFOM. The $\mathrm{OH}$ radical formation rates in photo-Fenton solution with and without DFOM, and $0.5 \mu \mathrm{M} \mathrm{H} \mathrm{H}_{2} \mathrm{O}_{2}$ solution were $(193 \pm 3.3),(7.2 \pm 0.6)$ and $(5.8 \pm 0.6) \times 10^{-12} \mathrm{M} \mathrm{s}^{-1}(n=3)$, respectively. The $\mathrm{OH}$ radical photoformation rate in the solution with DFOM was similar to that in a $0.5 \mu \mathrm{M} \mathrm{H}_{2} \mathrm{O}_{2}$ solution. These results indicate that the photo-Fenton reaction was suppressed by the addition of DFOM to the solution. Therefore, the difference between the photoformation rates of $\mathrm{OH}$ radicals with and without the addition of DFOM represents the $\mathrm{OH}$ radical formation rate derived from the photo-Fenton reaction. Furthermore, the $\mathrm{pH}$ value was essentially unchanged by the addition of DFOM.

Since the determination of $\mathrm{OH}$ radicals is based on competition kinetics, it is possible that a large amount of DFOM induced the consumption of $\mathrm{OH}$ radicals by DFOM, resulting in an underestimation of the $\mathrm{OH}$ radical photoformation rate. The effect of the addition of a variety of different DFOM concentrations $(0-10 \mu \mathrm{M})$ to a solution containing $1 \mathrm{mM}$ sodium nitrate as a source of $\mathrm{OH}$ radicals on the reaction of $\mathrm{OH}$ radicals with benzene was examined. Up to $10 \mu \mathrm{M}$ of DFOM showed no effect on the reaction of $\mathrm{OH}$ radicals with $1.2 \mathrm{mM}$ benzene (Fig. 2). It has been reported that the reaction rate constant of the $\mathrm{OH}$ radical with DFOM $\left(k_{\mathrm{DFOM}, \mathrm{OH}}\right)$ is $1.3 \times 10^{10} \mathrm{M}^{-1} \mathrm{~s}^{-1} \cdot{ }^{25}$ Using this rate constant, the first-order scavenging rate constant of DFOM $\left(k_{\mathrm{DFOM}, \mathrm{OH}} \times[\mathrm{DFOM}]\right)$ at $10 \mu \mathrm{M}$ was calculated to be $1.3 \times 10^{4} \mathrm{~s}^{-1}$. This calculated value was three orders of magnitude smaller than that of benzene at $1.2 \mathrm{mM}\left(1.56 \times 10^{7} \mathrm{~s}^{-1}\right)$ used in this study. Therefore, it is also demonstrated theoretically that the effect of $10 \mu \mathrm{M}$ added DFOM on the reaction of $\mathrm{OH}$ radicals with benzene is negligible.

Using the rain and river-water samples, the effect of the reaction time of DFOM with $\mathrm{Fe}(\mathrm{III})$ and that of the DFOM

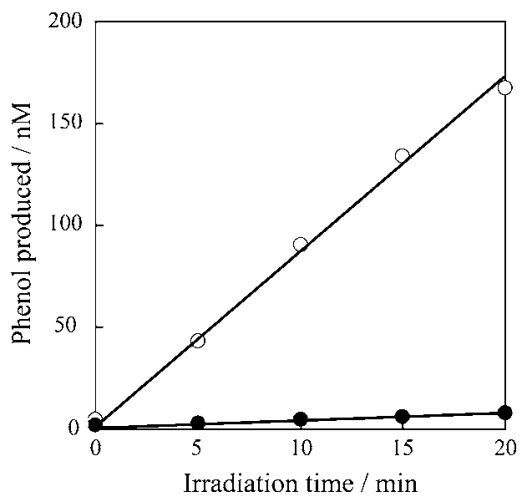

Fig. 1 Photoformation of the $\mathrm{OH}$ radical in a photo-Fenton solution (1 $\mu \mathrm{M}$ potassium trioxalate ferrate(III) and $0.5 \mu \mathrm{M}$ hydrogen peroxide) with $(\bullet)$ and without $(O)$ adding DFOM at $10 \mu \mathrm{M}$.

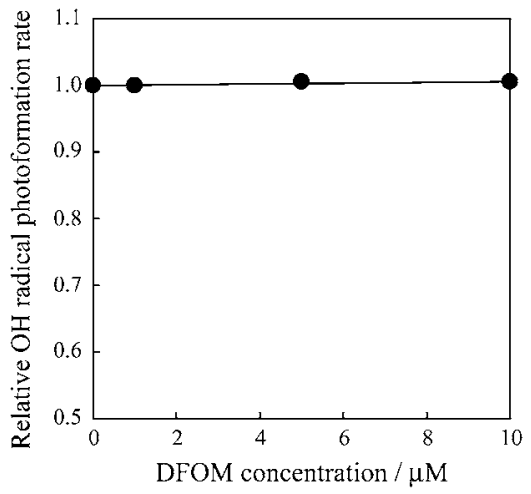

Fig. 2 Effect of the DFOM concentration on the $\mathrm{OH}$ radical photoformation rate in a solution containing of $1 \mathrm{mM} \mathrm{NaNO}$ as a source of the $\mathrm{OH}$ radical.

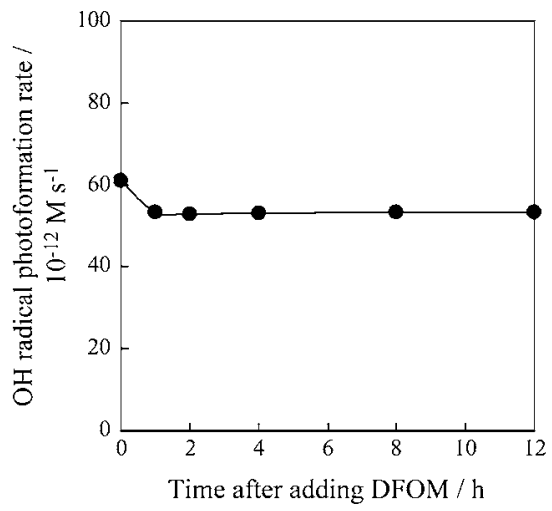

Fig. 3 Time-course studies showing the effect of $10 \mu \mathrm{M}$ DFOM on the $\mathrm{OH}$ radical formation rate in a river-water sample.

concentration on the suppression of the photo-Fenton reaction were examined. The $\mathrm{OH}$ radical photoformation rate of a riverwater sample at $1,2,4,8$ and $12 \mathrm{~h}$ after the addition of DFOM at a concentration of $10 \mu \mathrm{M}$ is shown in Fig. 3. One hour after the addition of DFOM to the river-water sample, the $\mathrm{OH}$ radical photoformation rate was fairly constant and remained this way over a time period of $12 \mathrm{~h}$. Therefore, the reaction time after the addition of DFOM to water samples was set at $1 \mathrm{~h}$. The $\mathrm{OH}$ radical photoformation rates at different DFOM concentrations 
Table 2 Summary of the $\mathrm{OH}$ radical photoformation rates and the calculated rates from each $\mathrm{OH}$ radical source in river and rain water samples

\begin{tabular}{|c|c|c|c|c|c|c|c|}
\hline & \multirow{2}{*}{$n$} & & \multirow{2}{*}{$\begin{array}{l}\text { Measured/ } \\
10^{-12} \mathrm{M} \mathrm{s}^{-1}\end{array}$} & \multicolumn{4}{|c|}{ Calculated from individual $\mathrm{OH}$ radical sources $/ 10^{-12} \mathrm{M} \mathrm{s}^{-1}$} \\
\hline & & & & Photo-Fenton & $\mathrm{NO}_{3}^{-}$ & $\mathrm{NO}_{2}^{-}$ & $\mathrm{H}_{2} \mathrm{O}_{2}$ \\
\hline \multirow[t]{2}{*}{ River } & 33 & Mean & 56.1 & 7.0 & 13.0 & 29.5 & $<0.1$ \\
\hline & & Range & $7.8-525.4$ & $0.7-45.8$ & $0.5-50.5$ & $<0.1-460.9$ & \\
\hline \multirow[t]{2}{*}{ Rain } & 9 & Mean & 57.9 & 11.4 & 6.2 & 8.6 & 20.7 \\
\hline & & Range & $25.0-118.0$ & $2.7-32.3$ & $1.8-24.7$ & $0.5-40.5$ & $2.1-38.4$ \\
\hline
\end{tabular}

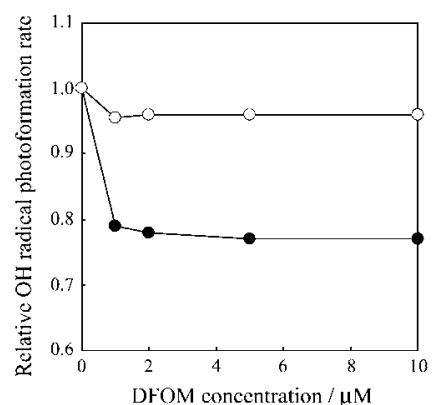

Fig. $4 \mathrm{OH}$ radical photoformation rate from the photo-Fenton reaction as a function of the DFOM concentration in river $(O)$ and rain $(\bullet)$ water samples.

$(0-10 \mu \mathrm{M})$ were determined in river and rain water samples. Representative results of the $\mathrm{OH}$ radical photoformation rates as a function of a variable DFOM concentration in river and rain water samples are shown in Fig. 4. The $\mathrm{OH}$ radical photoformation rates were constant at DFOM concentrations above $5 \mu \mathrm{M}$. In addition, the concentration of dissolved total iron in almost all of the rain and river water samples used in this study was less than $5 \mu \mathrm{M}$. Since DFOM can form a strong complex with $\mathrm{Fe}(\mathrm{III})$ at a 1:1 molar ratio, these results suggest that a DFOM concentration of $10 \mu \mathrm{M}$ is sufficient for suppressing $\mathrm{OH}$ radical formation from the photo-Fenton reaction in the river and rain water samples used in this study.

$\mathrm{OH}$ radical photoformation rates from photo-Fenton reactions in river and rain water

The photoformation rates of $\mathrm{OH}$ radicals in river and rain water samples are summarized in Table 2, which also gives the calculated photoformation rates of $\mathrm{OH}$ radicals from individual $\mathrm{OH}$ radical sources, such as the photo-Fenton reaction and the photolysis of nitrite ions, nitrate ions and hydrogen peroxide. The total photoformation rates measured were the same as those observed in our previous reports for river $\left(5.6-890.4 \times 10^{-12} \mathrm{M}\right.$ $\left.\mathrm{s}^{-1}\right)^{6}$ and rain (range: $\left.<0.5-330.3 \times 10^{-12} \mathrm{M} \mathrm{s}^{-1}\right)^{5}$ water samples. In river water, the $\mathrm{OH}$ radical photoformation rates from the photo-Fenton reaction determined by the difference between the $\mathrm{OH}$ radical formation rates with and without added DFOM were in the range of $0.7-45.8 \times 10^{-12} \mathrm{M} \mathrm{s}^{-1}$. In order to clarify the mechanism inducing the photo-Fenton reaction, the relationships between the $\mathrm{OH}$ radical formation rate from the photo-Fenton reaction and various chemical components (DOC, $\mathrm{H}_{2} \mathrm{O}_{2}$, total-iron and $\mathrm{FM}$ ) were examined. There was a strong positive correlation between the $\mathrm{OH}$ radical formation rate from the photo-Fenton reaction and the content of FM $(r=0.753)$ and DOC ( $r=0.587)$ (Fig. 5). The content of FM also exhibited a significantly positive correlation with the DOC concentration $(r=0.819, p<0.001)$. In our previous study, a strong positive correlation between $\mathrm{OH}$ radical formation from unknown sources (other than the direct photolysis of nitrite, nitrate and $\mathrm{H}_{2} \mathrm{O}_{2}$ ) and FM was observed in river water. ${ }^{6}$ The fluorescence intensity at an excitation wavelength of $320 \mathrm{~nm}$ and an emission wavelength of $420 \mathrm{~nm}$, as used in this study, can be used as a rough index of the amount of humic substances in river water samples collected in Hiroshima prefecture. ${ }^{26}$ Fukushima and Tatsumi reported that the photoreduction of Fe(III) is enhanced by addition of humic acids. ${ }^{27}$ Therefore, the positive correlation between the $\mathrm{OH}$ radical formation rate from the photo-Fenton reaction and FM suggests that the FM, such as humic substances, plays an important role in the photo-Fenton reaction in river water, while the detailed mechanism is not yet clear. In support of this view, Southworth and Voelker reported that $\mathrm{OH}$ radical formation was high in a synthesis solution of Suwanee River fulvic acid and $\mathrm{Fe}(\mathrm{III})$ and that DFOM eliminated $\mathrm{OH}$ radical formation. ${ }^{28}$

In rain water, the $\mathrm{OH}$ radical photoformation rates from the photo-Fenton reaction determined by the difference between the $\mathrm{OH}$ radical formation rates with and without added DFOM were in the range of $2.7-32.3 \times 10^{-12} \mathrm{M} \mathrm{s}^{-1}$. The relationship between the $\mathrm{OH}$ radical formation rate from the photo-Fenton reaction and the amount of FM in rain water was slightly positive ( $p<0.01, r=0.725$ ) (Fig. 6). The small fluorescence intensity in rain water, as compared to that in river water, indicated that the amount of FM, such as humic substances in rain water, is smaller than that in river water. In addition, the model calculation predicted that, in rain water, half of the dissolved $\mathrm{Fe}$ (III) forms a complex with humic substances and the rest of the $\mathrm{Fe}(\mathrm{III})$ is present as oxalate or hydroxide complexes, which are sources of photoproduced $\mathrm{Fe}(\mathrm{II}) .^{18}$ Therefore, it suggests that $\mathrm{OH}$ radical formation from the photoFenton reaction in rain water might be induced by the photochemical reduction of various $\mathrm{Fe}$ (III) complexes.

In our HPLC analysis of OH radical formation rates, the phenol concentrations in all river and rain water samples with and without added DFOM increased linearly with the irradiation time, suggesting that the photoformation of $\mathrm{H}_{2} \mathrm{O}_{2}$ during light irradiation has a insignificant effect on $\mathrm{OH}$ radical formation. ${ }^{3,29}$ In addition, there was no significant correlation between the $\mathrm{OH}$ radical formation rate from the photo-Fenton reaction and the $\mathrm{pH}$ value in river and rain water samples, while it is generally believed that the $\mathrm{pH}$ value of a solution affects the $\mathrm{OH}$ radical formation rate from the photo-Fenton reaction. ${ }^{24}$

The percentage contributions of the $\mathrm{OH}$ radical photoformation rate from the photo-Fenton reaction account for $2-29$ (mean: 15)\% of the total $\mathrm{OH}$ radical photoformation rate in river water (Table 3). Taking into account the photo-Fenton reaction, $33-110$ (mean: 80 )\% of $\mathrm{OH}$ radical sources in river-water samples were elucidated. It is expected that the percentage contributions over $100 \%$ observed in several 

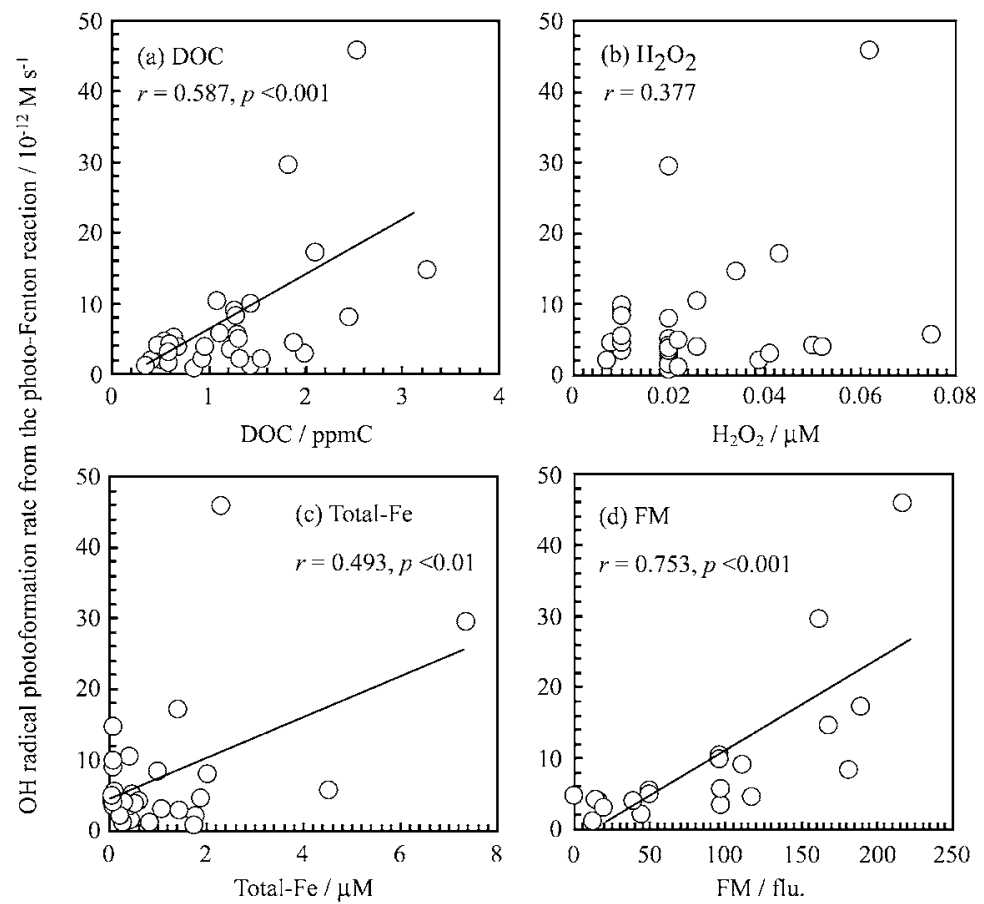

Fig. 5 Correlation between the $\mathrm{OH}$ radical formation rates from the photo-Fenton reaction and (a) DOC concentration, (b) $\mathrm{H}_{2} \mathrm{O}_{2}$ concentration, (c) total $\mathrm{Fe}$ concentration and (d) $\mathrm{FM}$ in the river water.
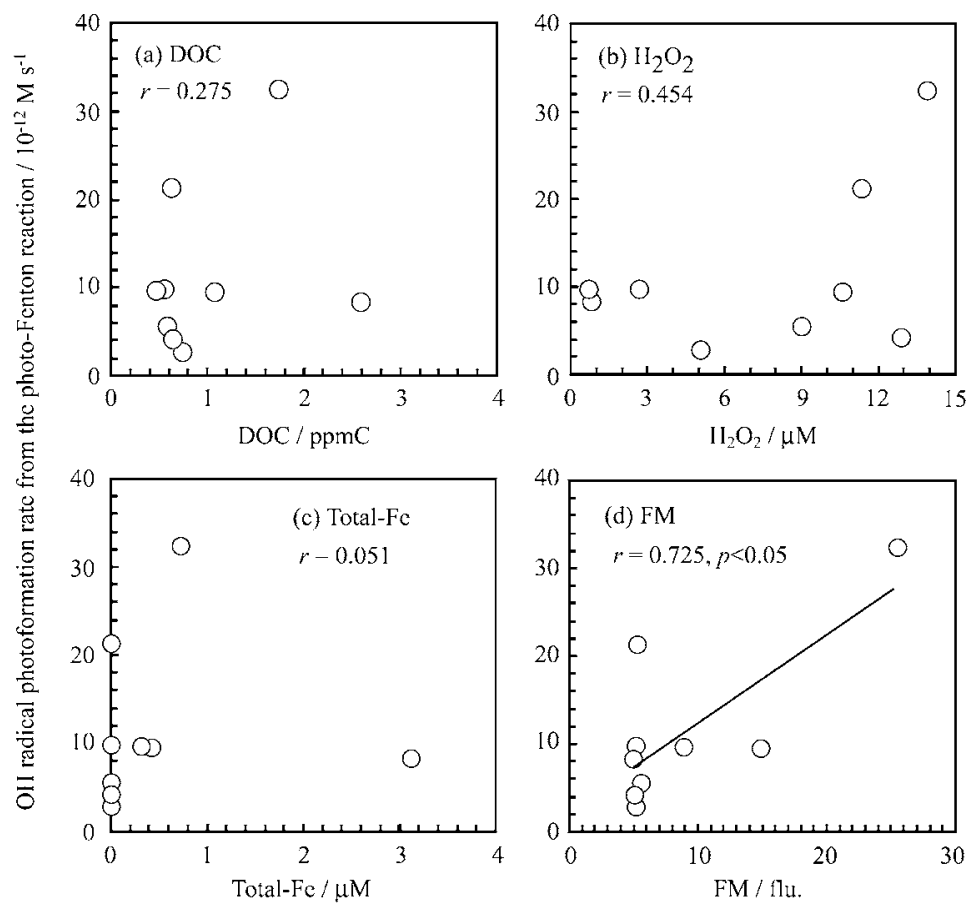

Fig. 6 Correlation between the $\mathrm{OH}$ radical formation rates from the photo-Fenton reaction and (a) DOC concentration, (b) $\mathrm{H}_{2} \mathrm{O}_{2}$ concentration, (c) total Fe concentration and (d) FM in the rain water.

river-water samples are attributable to measurement errors in both the observed and calculated values. The percentage contributions of the $\mathrm{OH}$ radical photoformation rates from the photo-Fenton reaction account for 5-38 (mean: 21$) \%$ of the total formation rates in rain water (Table 3 ). In addition to the photo-Fenton reaction, the contribution from the direct photolysis of $\mathrm{H}_{2} \mathrm{O}_{2}$, which is mainly derived from the dissolution of gas-phase $\mathrm{H}_{2} \mathrm{O}_{2}$ into atmospheric water, ${ }^{30}$ was an important source of $\mathrm{OH}$ radicals in rain water, whereas this was not the case for river water. Taking into account the photo-Fenton reaction and direct photolysis of $\mathrm{H}_{2} \mathrm{O}_{2}, 42$ to 110 (mean: 84)\% of $\mathrm{OH}$ radical sources in the rain-water samples were elucidated.

Our results presented in Table 3 suggest that there are still unknown sources of $\mathrm{OH}$ radical photoformation present in river 
Table 3 Percentage contribution of $\mathrm{OH}$ radical photoformation from each $\mathrm{OH}$ radical source in river and rain water samples

\begin{tabular}{lllccccc}
\hline & & \multicolumn{5}{c}{ Contribution, \% } \\
\cline { 4 - 8 } & $n$ & & Photo-Fenton & $\mathrm{NO}_{3}{ }^{-}$ & $\mathrm{NO}_{2}{ }^{-}$ & $\mathrm{H}_{2} \mathrm{O}_{2}$ & $\mathrm{Sum}^{\mathrm{a}}$ \\
\hline River & 33 & Mean & 15 & 33 & 31 & $<1$ & 80 \\
& & Range & $2-29$ & $3-70$ & $<1-89$ & & $33-110$ \\
Rain & 9 & Mean & 21 & 10 & 16 & 37 & 84 \\
& & Range & $5-38$ & $5-29$ & $<1-73$ & $3-74$ & $42-110$ \\
\hline
\end{tabular}

a. Sum of $\mathrm{OH}$ radical contributions from photo-Fenton, $\mathrm{NO}_{3}{ }^{-}, \mathrm{NO}_{2}{ }^{-}$ and $\mathrm{H}_{2} \mathrm{O}_{2}$.

and rain water samples. Direct photolysis reactions of chromophoric dissolved organic matter (CDOM), such as $p$ benzoquinone ${ }^{31}$ and humic substances, ${ }^{4}$ are possible sources of $\mathrm{OH}$ radicals in river water, though further study is needed to confirm this.

\section{Conclusions}

The rates of $\mathrm{OH}$ radical formation from the photo-Fenton reaction in river and rain water samples were determined by using DFOM, which can form a stable and strong complex with Fe(III), resulting in an inhibition of the photochemical reduction of Fe(III). The photo-Fenton reaction was suppressed by the addition of DFOM to water samples without interfering with the reaction of $\mathrm{OH}$ radicals with benzene and without affecting other photochemical reactions. The measurement results showed that the photoFenton reaction is one of the primary sources of $\mathrm{OH}$ radical photoformation in both river and rain water. Based on the correlation between the $\mathrm{OH}$ radical formation rate from the photo-Fenton reaction and FM in river water, it is suggested that FM, such as humic substances, plays an important role in photoFenton reaction. In contrast, it is expected that the photochemical reactions of various $\mathrm{Fe}$ (III) complexes induce the photo-Fenton reaction in rain water. In addition to the photo-Fenton reaction, the direct photolysis of $\mathrm{H}_{2} \mathrm{O}_{2}$ is an important process for $\mathrm{OH}$ radical formation in rain water. Taking into account the contribution of $\mathrm{OH}$ radical formation from the photo-Fenton reaction, more than $80 \%$ of $\mathrm{OH}$ radical sources in the river and rain water samples from Hiroshima prefecture were elucidated. It is speculated that one as yet unconfirmed source of $\mathrm{OH}$ radical photoformation present in both river and rain water samples is the direct photolysis of CDOM.

\section{Acknowledgements}

The authors thank the members of the Sakugawa and Takeda laboratories, Hiroshima University for their assistance with the collection of river and rain water samples and the measurement of environmental samples. This study was supported by the Ministry of Education, Culture, Sports, Science and Technology, Japan by a Grant-in Aid for Scientific Research (No. 18310010).

\section{References}

1. T. Mill, D. G. Hendry, and H. Richardson, Science, 1980, 207, 886 .
2. O. C. Zafiriou, J. Joussot-Dubien, R. G. Zepp, and R. G. Zika, Environ. Sci. Technol., 1984, 18, 358A.

3. T. Arakaki and B. C. Faust, J. Geophys. Res., 1998, 103, 3487.

4. P. P. Vaughan and N. V. Blough, Environ. Sci. Technol., 1998, 32, 2947.

5. T. Arakaki, T. Miyake, M. Shibata, and H. Sakugawa, Nippon Kagaku Kaishi, 1999, 1999, 335.

6. K. Takeda, H. Takedoi, S. Yamaji, K. Ohta, and H. Sakugawa, Anal. Sci., 2004, 20, 153.

7. N. Nakatani, N. Hashimoto, and H. Sakugawa, "Geochemical Investigations in Earth and Space Science: A Tribute to Issac R. Kaplan", ed. R. J. Hill, J. Leventhal, Z. Aizenshtat, M. J. Baedecker, G. Claypool, R. Eganhouse, M. Goldhaber, and K. Peters, 2004, The Geochemical Society, Great Britain, 233.

8. K. Takeda, H. Shindo, N. Nakatani, and H. Sakugawa, $J$. Jpn. Soc. Wat. Environ., 2005, 28, 509.

9. G. V. Buxton, C. L. Greenstock, W. P. Helman, and A. B. Ross, J. Phys. Chem. Ref. Data, 1988, 17, 513.

10. W. R. Haag and C. C. D. Yao, Environ. Sci. Technol., 1992, 26, 1005.

11. P. L. Brezonik and J. Fulkerson-Brekken, Environ. Sci. Technol., 1998, 32, 3004.

12. D. L. Sedlak and A. W. Andren, Environ. Sci. Technol., 1991, 25, 1419.

13. S. N. Pandis and J. H. Seinfeld, J. Geophys. Res., 1989, 94, 1105.

14. J. Mack and J. R. Bolton, J. Photochem. Photobiol., A, 1999, 128,1 .

15. R. Zellner, M. Exner, and H. Herrmann, J. Atmos. Chem., 1990, 10, 411.

16. B. M. Voelker, F. M. M. Morel, and B. Sulzberger, Environ. Sci. Technol., 1997, 31, 1004.

17. M. Fukushima, K. Tatsumi, and S. Nagao, Environ. Sci. Technol., 2001, 35, 3683.

18. R. J. Kieber, D. R. Hardison, R. F. Whitehead, and J. D. Willey, Environ. Sci. Technol., 2003, 37, 4610.

19. E. M. White, P. P. Vaughan, and R. G. Zepp, Aquat. Sci., 2003, 65, 402 .

20. R. C. Johnson, J. Chem. Educ., 1970, 47, 702.

21. N. Nakatani, N. Hashimoto, H. Shindo, M. Yamamoto, M. Kikkawa, and H. Sakugawa, Anal. Chim. Acta, 2007, 581, 260.

22. K. Fujiwara, T. Ushiroda, K. Takeda, Y. Kumamoto, and H. Tsubota, Geochem. J., 1993, 27, 103.

23. H. Sakugawa, T. Yamashita, H. Kawai, N. Masuda, N. Hashimoto, S. Makino, N. Nakatani, and K. Takeda, Chikyukagaku, 2006, 40, 47.

24. R. G. Zepp, B. C. Faust, and J. Hoigne, Environ. Sci. Technol., 1992, 26, 313.

25. S. Hoe, D. A. Rowley, and B. Halliwell, Chem.-Biol. Interact., 1982, 41, 75 .

26. K. M. G. Mostofa, Y. Honda, and H. Sakugawa, Geochem. J., 2005, 39, 257.

27. M. Fukushima and K. Tatsumi, Colloids Surf., A, 1999, 155, 249.

28. B. A. Southworth and B. M. Voelker, Environ. Sci. Technol., 2003, 37, 1130.

29. T. Arakaki, Y. Kuroki, K. Okada, Y. Nakama, H. Ikota, M. Kinjo, T. Higuchi, M. Uehara, and A. Tanahara, Atmos. Environ., 2006, 40, 4764.

30. H. Sakugawa, I. R. Kaplan, W. Tsai, and Y. Cohen, Environ. Sci. Technol., 1990, 24, 1452.

31. A. E. Alegria, A. Ferrer, and E. Sepulveda, Photochem. Photobiol., 1997, 66, 436. 